\title{
INDIVIDUAL AND ORGANIZATIONAL IDENTITIES IN MERGER CONTEXTS: A BOUNDARY PERSPECTIVE
}

\author{
BRUNO FELIX ${ }^{1}$ \\ iD https://orcid.org/0000-0001-6183-009X \\ MÁRIO S. BENTO ${ }^{1}$ \\ (iD) https://orcid.org/0000-0002-7183-0779
}

To cite this paper: Felix, B., Bento, M. S. (2018). Individual and organizational identities in merger contexts: A boundary perspective. Revista de Administração Mackenzie, 19(4). doi:10.1590/16786971/eRAMG170104

Submission: Oct. 5, 2017. Acceptance: Jun. 7, 2018.

Fucape Business School, Vitória, ES, Brazil.

\section{(c)) BY}




\section{ABSTRACT}

Purpose: To understand the boundary dynamics between organizational and individual identities that are negotiated in mergers.

Originality/value: This was the first study to explore the interface of the boundaries between individual and organizational identities in merger contexts.

Design/methodology/approach: The results are presented as a grounded theory based on interviews with 64 individuals from 16 different companies that have undergone mergers.

Findings: We analyzed conflict, intrusion, distance and balance as consequences of internal and external identity boundaries' (in) congruence between organizations and discussed how companies can minimize individual and organizational (of the merged company) identity conflicts through boundary work. Furthermore, we discussed the relationships between organizational and individual identity boundaries. The grounded theory we developed held that the degree of permeability between the internal and external boundaries between the organizations involved in a merger determines the types of episodic events and permanent states of conflict between organizational identities. In general, our study contributes to a holistic and comprehensive vision of how the boundaries between identities at the organizational and individual levels contribute to identity formation and the retention of individuals in the new merged organization. Suggestions for practice and for future researches are provided.

\section{KEYWORDS}

Boundaries. Merger. Organizational identity. Individual identity. Grounded theory. 


\section{INTRODUCTION}

In recent decades, more than 40,000 mergers and acquisitions (M\&As) have occurred around the world involving amounts that exceed US\$ 5.5 trillion (Cho, Lee, \& Kim, 2014). During this period, with rising competition in an increasingly global market, mergers have been used as a growth strategy to add successful brands to a portfolio (Joseph, 2014), to increase market share and to reduce costs by capturing operational synergy (Dick, Ullrich, \& Tissington, 2006; Vieru \& Rivard, 2014). However, more than half of mergers do not achieve the expected, partly because of individual and organizational responses to change processes following the implementation of these partnerships (He \& Brown, 2013). Thus, the interface between individual and collective identities has emerged as one of the critical factors for successful mergers (Vieru \& Rivard, 2014).

Given this context, studies have sought to understand how the identity construction and confrontation process takes place in the merger context. Some studies have been devoted to analyzing the actors that determine the formation of a new organizational identity (Fiol, 2002; Vieru \& Rivard, 2014) as well as the process of deconstructing the identity of the former organizations and constructing the new organizational identity (Joseph, 2014; Ullrich, Wieseke, \& Dick, 2005), thus assuming organizational identity to be a homogeneous and integrative construct. Other studies have adopted a more differentiated perspective by analyzing the influence of status differences between the former organizations and the resulting coexistence of different and simultaneous identities in the new organization (Cho et al., 2014; Rouzies, 2011). In addition, some studies have been conducted to understand the boundary dynamics between the group identities in a post-merger organization (Terry, Carey, \& Callan, 2001) and between the multiple identities of a hybrid organization and its members (MacLean \& Webber, 2015).

Despite the contributions provided by these studies, there are still opportunities for advances in the literature on identity in M\&As. There is a need to understand the phenomenon from a multi-level perspective to simultaneously consider organizational and individual aspects. For doing so, it is possible to apply the advances that have already been made in the literature on the boundary dynamics between organizational and individual identities (Kreiner, Hollensbe, \& Sheep, 2006) to the literature on identities in the context of M\&As. Boundaries are co-constructed delimitations that 
separate domains from each other (Clark, 2000)—in this case, two organizations involved in a merger or an organization and individuals-and may vary as to their degree of permeability. Less permeable boundaries give more autonomy and predictability to the entity (organization or individual) that adopts them (Ashforth, Kreiner, \& Fugate, 2000; Rau \& Hyland, 2002); boundaries are therefore an important lens for a better understanding of the identity conflicts that occur at the individual and group levels in mergers and how these conflicts are overcome.

This study thus aimed to understand the boundary dynamics between organizational and individual identities that are negotiated in mergers. We analyzed conflict, intrusion, distance, and balance as consequences of internal and external identity boundary (in) congruence between organizations and discussed how companies can minimize individual and organizational (of the merged company) identity conflicts through boundary work. Furthermore, we discussed the relationships between organizational and individual identity boundaries. The results are presented as a grounded theory based on interviews with 64 individuals from 16 different companies that have undergone mergers. In the pre-merger period, the relationships between the organizations are analyzed; in the post-merger period, the analysis extends to the relationship between the individual and organizational levels of analysis.

This study provides theoretical and practical contributions. In theoretical terms, the use of boundary theory and the boundary dynamics approach in the literature on identities in mergers allows advances to be made in the theoretical knowledge on how permeability between the internal and external boundaries of the involved entities produces identity balance or conflict. In practical terms, we present a model that provides organizations and individuals involved in mergers with an analytical lens to better understand the relationships between the involved identities as well as to predict possible conflicts and action plans that can minimize such conflicts and promote more fluid mergers.

\section{INDIVIDUAL AND ORGANIZATIONAL IDENTITIES}

Identity is a widely discussed concept at the individual (Petriglieri, 2011) and organizational levels (He \& Brown, 2014; Brown, 2017) as well as at both levels simultaneously (Kreiner et al., 2006). The idea that individuals have multiple competing and complementary identities that are 
socially activated according to the principle of salience has been recurrent in the literature (Stryker, 1981). Similarly, some authors have presented the idea that individuals make multiple conceptualizations about who they are as an organizational collective (Hsu \& Elsbach, 2013) based on the hierarchical categories and positions to which they are assigned (Curchod, Patriotta, \& Neysen, 2014).

This topic has also been studied using a more structuralist approach in which identities are viewed with greater stability and permanence as well as from an approach focused on agency, which sees identities as more malleable and temporary (Brown, 2015). Besides the dichotomy between the structuralist and micro-level interaction (agency) approaches, it is possible to notice that the agency-structure dynamic also has defenders. For example, Stryker (1981) and Markus and Kunda (1986) argue that some identities tend to be more stable and therefore remain salient in different contextual situations. At the same time, these authors also suggest that other non-core identities tend to be less tied to immediate social circumstances and are therefore less stable.

This discussion about identity stability applies to both the individual and organizational levels of analysis (Stryker, 1981). Some more permanent aspects of the individual's self are derived from personal characteristics; however, as they interact with different social groups, individuals may claim membership and thus assume new identities (Allen, Wilder, \& Atkinson, 1983; Burke, 1984; Tajfel \& Turner, 1986). These identities vary in terms of degree of salience and their potential to be activated in certain immediate social situations.

In turn, organizational identity is constructed from its members' perception of what makes them unique and distinctive (Dutton, Dukerich, \& Harquail, 1994). The literature is extensive with regard to the stability and adaptability of organizational identities over time (Cornelissen, 2002; Gioia, Schultz, \& Corley, 2000). Here, we adopt the understanding that an organization has different identities that vary in their degree of salience (Albert \& Whetten, 1985; Pratt \& Foreman, 2000), which means that some are more stable and others are more subject to change (Kjaergaard, Morsing, \& Ravasi, 2011; Ravasi \& Schultz, 2006; Sillince \& Brown, 2009). These different identities, when they are not compatible with each other, produce a state of conflict (Glynn, 2000). It is thus understood that individual and organizational identity are multiple, vary in terms of stability and change, and are activated in specific situations according to the principle of salience (Kreiner et al., 2006). Boundary theory is an interesting theoretical lens for 
understanding the relationship at the different levels and dimensions of identity involved in a merger between two or more organizations.

\section{BOUNDARY THEORY}

Boundary theory is dedicated to analyzing the ways in which people simplify and classify objects, entities, places, and situations to create, maintain and move boundaries that delimit different domains (Ashforth et al., 2000). Boundaries separate domains from each other and enable and constrain how these domains are connected and related. A domain is "a cognitive space of what is included within the boundary" (Kreiner et al., 2006, p. 1319), and "boundaries" are physical, temporal or symbolic co-constructions that demarcate how domains are separated from one another (Clark, 2000; Rau \& Hyland, 2002). For example, an individual can be viewed as one domain and a company as another domain. Similarly, two companies involved in a merger can be viewed as two different domains. These boundaries are characterized by their degree of permeability, which is the degree to which the elements of one domain can enter the other (Hall \& Richter, 1988). For example, in a merger, there may be high permeability between the companies' visual identities when the merged company's logo includes visual elements from the brands of the companies involved in the process. It is also possible, however, for there to be low permeability between the brands, i.e., when they are retained without any degree of intersection between the elements that compose them. Boundaries are thus classified as a bipolar, continuous dimension; boundaries with low permeability are thin/weak and those with high permeability are thick/strong (Ashforth et al., 2000). Thin/weak boundaries allow integration between domains, while thick/strong boundaries promote segmentation between domains (Hartmann, 1991).

Boundaries may vary in terms of the location where they are constructed (Clark, 2000): some are positioned around the perimeter of a domain (external boundary), while others are located within a domain (internal boundary). Thus, external boundaries serve to delimit the separation between domains (Hartmann, 1991). In this study, they serve to show the delimitation between two entities, which may be two organizations involved in a merger or an individual and an organization. Similarly, internal boundaries delimit the subdivisions within a domain (Schneider, 1991). For example, this study cites the different organizational identities a company 
may have according to the hierarchical categories and positions to which its members are assigned (Curchod et al., 2014). Internal boundaries can thus delimit the identities of a single organization as "lucrative", "sustainable" or "hostile", for example.

Although most studies that apply the boundary theory do so using only an analysis of external boundaries, some previous studies have analyzed both internal and external boundaries (e.g., Dreiss, 1986), and some of these have been in the organizational context (e.g., Fiol, 1989; Kreiner et al., 2006).

\section{INDIVIDUAL AND ORGANIZATIONAL IDENTITIES IN THE CONTEXT OF MERGERS: A BOUNDARY PERSPECTIVE}

Few studies have simultaneously analyzed multiple identities at the individual and organizational levels of analysis, and even fewer have done so considering the interfaces between identities within and between individuals and organizations (Horton, Bayerl, \& Jacobs, 2014; Kreiner et al., 2009; MacLean \& Webber, 2015). In this study, we propose to apply the multi-level (individual and organizational) and multiple identity (delimited by internal and external boundaries) perspectives at each level of analysis in the context of mergers. To understand the relationships between the internal and external identities of individuals and organizations, we base our analysis on Kreiner et al. (2006) and MacLean and Webber (2015) and consider two types of boundary interfaces between the identities involved: intra-identity boundary interfaces (within identity) and inter-identity boundary interfaces (between individual and organizational identities). Accordingly, as sensitizing concepts for our research, we consider the idea that we can have integrated or segmented external boundaries (between two organizations or between an individual and an organization) and also integrated or segmented internal boundaries between the multiple identities of individuals and/or organizations. We also consider the concept of boundary incongruence (Kreiner et al., 2006), which refers to incompatibility in the degree of permeability between the internal and external boundaries between two entities. An example of boundary incongruence is when one organization adopts thick boundaries in relation to its external environment, thus promoting segmentation between domains, and the other has thinner boundaries with greater openness to integration between the involved domains. 
In this study, we constructed our analysis based on two different moments: during and post-merger. During the merger, we emphasized the relationship between the organizations and were guided by the following research questions:

1. What are the consequences of internal and external boundary incongruence for the organizations involved in a merger?

2. What types of boundary violations can occur between the companies involved in a merger?

3. When boundary violations become recurrent, how can organizations minimize these problems?

Finally, in the post-merger period, we sought to understand:

4. How do individuals react to conflicts between their personal identities and the organizational identity of the merged company?

\section{METHODOLOGY}

This qualitative study was conducted based on in-depth interviews with 64 employees from 16 companies that have undergone a merger with the aim of developing a grounded theory (Glaser \& Strauss, 1967) to understand how the boundary dynamics between individual and organizational identities occur in merger contexts.

The participating organizations and individuals were selected according to the following criteria: the human resources departments of 32 Brazilian companies listed as having undergone mergers in the three years prior to the study were contacted and invited to participate. These companies are all large, with more than 1000 employees. A total of 22 companies agreed to participate in the study. Following the principle of theoretical sampling (Glaser \& Strauss, 1967), the selection of the individuals and organizations that comprised the sample was based on the research questions that arose during the study's development.

At the end of data collection, 64 individuals from 16 different companies were interviewed; there were four individuals from each participating company. The sectors included in the data collection stage were information technology (4), financial (4), food and beverage (3), utilities (2), logistics (1), education (1) and textiles (1). In all cases, the interviews involved two employees from each of the two companies involved in the merger, one at the managerial level or higher and another one in a non-leadership position. 


\section{RESULTS}

In this section, we present a set of propositions that describe the boundary dynamics of identities during (propositions 1 through 6 ) and after the merger (propositions 7 and 8). They expound upon the internal and external boundary violations that may occur between the organizations involved in the merger (propositions 1, 2 and 3), the types of boundary violations between the organizations (proposition 4), the identity conflicts and promotion of identity balance between the organizations involved in the merger (propositions 5 and 6) and the boundary dynamics between individual identity and the merged organization's identity (propositions 7 and 8).

\subsection{Organizational boundaries in mergers}

In this section, we discuss the organizational boundaries between institutions during a merger and seek to answer research questions 1, 2 and 3.

\subsubsection{Internal and external boundary violations between organizations}

Through our first research question, we sought to understand the consequences of internal and external boundary incongruence for the organizations involved in a merger. In this section, based on the following accounts, we discuss two types of consequences: internal and external organizational boundary violations.

The most difficult thing for us is that they were two companies with a lot of personality. Everything was very well-defined. One company was focused on sustainability and personalized service, and the other was focused on low costs (retail). There were a lot of clashes between the essences of both companies; things like that always happened, and they were a hassle!

The problems here had to do with the fact that there wasn't just one company here and another one over there. The people over there had different ideas about their company, and so did we. One group over there saw the company as hierarchical, and another one saw it as 
more innovative. Here, there was a person who saw the company as aggressive, and others saw a peaceful and loving group, and this has to do with everyone's experience and position. So there were different kinds of problems (interviewee 33).

What we call organizational boundary violations are episodic situations in which the delimitations between identities are treated in such a way that they produce a clash of expectations regarding the desired degree of permeability between them. In the first example, the respondent reports a "clash of essences", which characterizes an external organizational boundary violation. Conversely, in the second example, the clashes refer to the fact that people have different experiences in organizations that make them perceive different and simultaneous collective identities, and these identities may be incompatible with each other. While some would prefer these internal identities to coexist independently, others would choose a model in which the internal identities influence each other. In specific situations, there may be incompatibilities where the individuals expect greater or lesser compatibility of the internal boundaries between the organizations, which characterizes an internal organizational boundary violation.

Proposition 1: In mergers, violations of organizational identity that occur between the involved institutions can be characterized as external organizational boundary violations when they are related to the organization's core identity, or internal organizational boundary violations when they are related to the degree of similarity in people's definitions of the organizations.

In a merger, two or more companies, each of which with a certain degree of permeability to their external and internal boundaries, have their identities confronted. In two of the 16 mergers studied, there were reports that both organizations had very defined and stable core identities. In these cases, the accounts signaled that there were many occasions when individuals in both organizations experienced episodes where there was mutual inflexibility perceived by members of both organizations in terms of adopting behaviors associated with the other organization's identity or giving up core aspects of the original organization that they worked for before the merger.

The situations in which there were problems had to do with the companies' essences. The company's employees were never very accepting of the different behavior of other companies that came to provide services here, and they were also the same way. So there were 
two companies that knew what they were and that they were very different from each other (interviewee 4).

In the three organizations in which both organizations were interpreted as having greater openness to the identity of their merger partner, the study participants reported that there were few situations where the organizations' members experienced clashes in expectations about the merged organization's identity. Different respondents suggested that the convergence process to the new organization's identity was fluid and harmonious, as illustrated in the following statement:

Both companies had a weak, more malleable culture and a more fluid identity. Since we came from a culture of mergers and exchange, it was natural for us to be open to absorbing things from the personality of other companies. So the whole process was very easy and peaceful. The new organization we created as a result of this merger grew with a merging of identities, which naturally created a new identity (interviewee 9).

Based on these illustrations, we present the following propositions:

Proposition 2a: When both companies involved in a merger have more central and distinctive identities (thick external boundaries), there tend to be external organizational boundary violations.

Proposition 2b: When the companies involved in a merger have identities that are more subject to ongoing interpretation and change (thin external boundaries), there tend to be few external organizational boundary violations.

The contact between different organizational identities that occurs in a merger also has consequences for internal organizational identity boundaries. Our data allowed us to also note the clashes of expectations that occurred in terms of how people addressed the boundaries between organizational identities. As reported in three of the studied mergers, such conflicts particularly occurred in mergers where the respondents viewed both organizations as having thick boundaries between internal identities.

In both companies, there were people who had different definitions for who we are, and this created a lot of isolation. In our company, the people who saw it as a company of privileged people had no contact with those who saw it as exploitative. There was also a lot of segmentation in their company; the ones with high-level positions saw it as a 
company where no one's position was secure, while the peons saw the company as a place to grow. Both had groups with their own views of the company, without much exchange. So when they merged, there were a lot of self-righteous people who weren't willing to see the other side. It was hard to coexist (interviewee 57).

In this account, it is clear that the multiple internal identities of each organization were rigid, which therefore created "uncomfortable" situations in which roles were unclear, and this lack of clarity had consequences for the harmony between the internal identities. However, when the internal identities were more fluid, which occurred in three of the 16 companies involved in the study, the ambiguity between the internal identities did not disrupt the harmony between the relationships because the ambiguity was expected, as noted in the following account:

We both had a model of job enrichment, more flexible and fluid positions according to the project, more ambiguous roles and, in short, more flexibility in the roles and in how things work within the company. There was a culture of respecting the other group's interpretation and dealing with it well. So, we didn't have much trouble dealing with this post-merger identification (interviewee 61).

Based on this understanding, we propose that:

Proposition 3a: When both companies involved in a merger have more rigid and stable internal identities (thick internal boundaries), there tends to be internal organizational boundary violations between the merging companies.

Proposition 3b: When both companies involved in a merger have internal identities that are more subject to ongoing interpretation and change (thin internal boundaries), there tends to be few internal organizational boundary violations between the merging companies.

\subsubsection{Types of boundary violations between organizations}

What types of boundary violations can occur between the companies involved in a merger? To respond to our second research question, we first discuss different types of internal and external boundary violations, and then we present the idea that recurring episodic boundary violations leads to a more permanent state of identity conflict. 
Most of the respondents reported that their original organizations had different levels of permeability in their external boundaries. Thus, individual accounts regarding the nature of boundary violations differed. Here, we present two types of external boundary violations: distance and intrusion. We use external boundary distance violations to describe the boundary violations experienced by individuals in organizations where there was an expectation of maintaining a homogeneous and stable identity in the new organization, but the members of the other organization involved in the merger adopted a position of greater integration between organizational identities. The following statement illustrates this situation.

They didn't want come to an agreement with us, for example, on the issue of our identity being more aggressive as a whole, of no one using our competitors' products, of having a certain hostility towards our competitors. They were always avoiding it, as if we were making them uncomfortable, forcing an identity they wanted to stay away from, without making a commitment to a behavior that was agreed upon by everyone (interviewee 28).

In the next situation described, the members of one organization were eager for a greater integration of organizational identities until they were confronted with the domineering position of the individuals working in the other organization and then they perceived an identity intrusion. We call this dynamic an external boundary intrusion violation, as illustrated by the following quote:

We had no need for such a marked identity. We were open to new things, to other ways of being seen, but since they came as authoritative, suggesting that we had to adhere to their model or some other new model being created, it got a little complicated, and many of us felt disrespected and invaded (interviewee 19).

Hence, we propose the following:

Proposition 4a: When one of the organizations involved in a merger has a more distinctive organizational identity (thick external boundary), and the other has an organizational identity that is more subject to ongoing interpretation and change (thin external boundary), the members of the former tend to indicate the presence of external organizational boundary distance violations and the members of the latter tend to indicate external organizational boundary intrusion violations. 
Similarly, there are different types of internal boundary violations when organizations present different degrees of permeability between their multiple identities. Internal organizational boundary distance violations are boundary violations experienced by individuals from a merging organization in which there is an expectation of maintaining multiple coexisting identities in a segregated manner, while in the other merging organization, there is a preference for integration of the identities. One way to segment the identities of "glamorous", conferred by the top hierarchy, and "punitive", attributed to the top hierarchy by the low-level workers, would be to promote a low integration between the people who define "who we are" based on these terms. The integration of internal identities would involve allowing the groups that define the organization in different ways to interact and find a synthesis or confluence of their definitions.

Conversely, internal organizational boundary intrusion violations are boundary violations perceived by individuals who would expect to integrate multiple coexisting identities, while in the other organization there is a preference for segmenting the identities. The following quote illustrates this type of violation from the perspective of distance and intrusion:

We were more rigid, we followed formal procedures for everything, and we had a lot of hierarchy. There were people in our company in higher positions who saw the company as glamorous and there were subordinates who saw the company as punitive; there were different identities at the same time, and we tried to leave these views pretty segregated. They were different; they didn't like having to document anything, they were very informal and depending on the group, they had their own interpretation; the Finance staff saw the company as disorganized, and those in Marketing saw it as modern, but this was normal for them. Their slogan was productive chaos. So they felt pressured by us, they told me this a few times [intrusion]. It created problems at different levels. From our side, there was the perception that they were being sloppy with these processes, that they were ignoring important things and patterns [distance] (interviewee 51).

We thus suggest the following:

Proposition 4b: When one of the companies involved in a merger has a more distinctive organizational identity (thick internal boundaries), and the other has an organizational identity that is more subject to ongoing interpretation and change (thin internal boundaries), the members of the 
former tend to indicate the presence of internal organizational boundary distance violations and the members of the latter tend to indicate internal organizational boundary intrusion violations.

\subsubsection{Identity conflicts and the promotion of identity balance between organizations}

When boundary violations become frequent, how can organizations minimize these problems? In response to the third research question, we initially found that the recurrence of boundary violations led to a more permanent state of conflict due to incompatibility between the social actors' expectations about the degree of permeability between the internal and external boundaries of the merged organizations. We call this phenomenon identity conflict, which may occur as a result of external or internal boundary violations. In the first case, we classify them as distinctiveness conflicts, because they create a state of incompatibility between what makes the organizations unique; in the second case, we call them socialization conflicts, because they reveal a state of incompatibility between the individuals' propensity to integrate or segment the multiple identities that characterize who they are as a collective. Below, we present two pieces of empirical evidence that illustrate distinctiveness and socialization conflicts, respectively.

These situations of seeing our company's identity being violated kept accumulating. It was the color, the brand, the culture of aggressiveness. Everything was dying, and we went into crisis, an endemic crisis [conflict of distinctiveness].

The people's freedom to see themselves and classify themselves in this or that way was changing. We let everyone classify things and themselves in their own way and to each of their own. They had a lot of exchange, they dealt better with the ambiguity of these classifications that people make, the labels they give to the company. Small problems kept cropping up here and there, and after a while, it became unbearable [conflict of socialization] (interviewee 64).

This evidence led us to propose the following:

Proposition 5: When external organizational boundary violations are recurrent, they tend to lead to a widespread state of distinctiveness conflict 
(external boundaries), while when internal organizational boundary violations are recurrent, they tend to lead to a widespread state of socialization conflict (internal boundaries).

To resolve these conflicts, the respondents said that, over time, the merged company sought to construct homogeneous patterns for the degree of flexibility between the internal and external organizational boundaries. These efforts by the merged organization allowed the negative consequences of the distinctiveness and socialization conflicts to be eased and are here called organizational boundary work tactics.

At one point, the group who led the merger began to articulate actions to manage what the new company that was forming would be. Would it be more closed, stronger in terms of culture, or would it be more open? We saw that it ended up being stronger. . . . They were also internally defining how the company would work in terms of internal things, how the work would function, the positions, the hierarchies, the processes. Over time, we saw that they chose to design a more lateral internal structure (interviewee 36).

This example illustrates the active role played by the groups that led the merger in the sense of seeking to promote greater consistency in expectations about the nature of the relationships between the organizational identities. This discussion leads us to the following proposition:

Proposition 6: Organizational boundary work tactics decrease internal and external organizational boundary violations, thus minimizing the chances of external distinctiveness conflicts and internal categorization conflicts.

\subsubsection{Organizational and individual identity boundaries post-merger}

Up to this point, our propositions have referred to phenomena that occur before and during a merger, always with an emphasis on the organizational level of analysis. To respond to the fifth research question, we will discuss the relationship between individual identity and the merged organization's identity. Thus, the article's focus shifts to the individual and organizational levels of analysis. We maintain the idea that organizational identity may, to a greater or lesser degree, overlap with the self-identity and that individual satisfaction with this degree of overlap has implications for the individual's identity stability in the workplace. Here, we should 
emphasize that we are referring to individual identity using an integrated vision, thus considering only its external boundaries. In the same way, we also consider collective organizational identity without taking into account the different coexisting organizational identities. The quote below is one respondent's account of the incompatibility that he began to experience between his identity and that of the merged organization, which we will call individual-organization external identity conflict.

The company born from the merger made me a bit uncomfortable because it no longer has anything to do with me. It doesn't look anything like me; it isn't a place I would choose to work today. But you know how it is, I have already been there for a while, I have a whole history there. So I have to adjust myself or adopt a character that better fits the company or even change and let some different things into my life, ... for example, to be more careful about letting my personal life spill into the workplace. If this doesn't happen, I'm going to end up leaving (interviewee 18).

In this case, the respondent presents the interpretation that there is less overlap between his personal identity and that of the organization. He suggests that he does not see himself included in the post-merger organizational "we" and that this lack of fit demands a change in the degree of permeability in the boundaries between his personal identity and organizational expectations. Thus, adopting a more integrated or segmented position in relation to the work domain seems to be a suitable strategy for finding balance in the relationship between the personal identity and the organization's identity; if this adjustment does not occur, the continuity of his connection to the company may be comprised. We thus propose the following:

Proposition 7a: When an individual understands that there is incongruence between his or her identity and the merged organization's identity (individual-organization external conflict), there is a state of individual-organization external identity conflict, which tends to lead to changes in the degree to which the individual adopts segmented or integrated boundaries in relation to the work domain. If this change is not made, the individual tends to leave the organization.

Conversely, some participants revealed that they had experienced a harmonic relationship in terms of individual and organizational identities. In these cases, the merged organization showed itself to be adherent to the self, with either a greater or lesser degree of permeability between identity 
boundaries. This state of fit between the expectations about the boundaries between individual and professional identities is what we call individual-organization external identity balance. As illustrated by the quote below, we found evidence that this state tends to lead to the promotion of a desire for permanence in the merged organization.

After the merger, the company was different, but I feel pretty calm; I still see myself in the company. It's different, but I also can see a lot of me there. So I don't think it has affected me, or my identity. I will continue being myself, being who I am (interviewee 45).

We thus present the following proposition:

Proposition $7 \mathrm{~b}$ : When an individual understands that there is congruence between his or her individual identity and the organizational identity of the merged company (individual-organization external balance), there is a state of individual-organization identity balance, which tends to lead to stability in the degree to which the individual adopts segmented or integrated boundaries between the self and the work and the individual's continuity in the merged organization.

As previously discussed, our understanding here is that individuals and organizations have multiple identities, which indicates that there may be conflicts between individual and organizational identities across levels of analysis. We identified respondents who perceived that some aspects of their individual identity (did not) fit certain aspects of the organizational identity, which we call individual-organization internal conflict. For example, this situation occurred with a respondent who defined himself as "dedicated to work" and a "faithful member of a church." For this participant, these identities changed to different degrees, according to one aspect of the perceived organizational identity, which he defined as "time-demanding" when he suggested that the merged organization constantly requested that he took weekend trips. While his personal identity of "dedicated to work" adjusted well to this aspect of the organizational identity, the "faithful member of a church" identity showed a lack of fit because his voluntary religious work on weekends was compromised by his decision to agree to the company's requests.

I'm a faithful member of a church, but I'm also very devoted to work. I was always able to reconcile this in the company where we 
worked. . . . After the merger, it became more complicated because they began to ask me to work on weekends. During the week they're flexible, but on weekends they demand a lot of time, especially now that I've become regional director (interviewee 52).

In this case, the individual evaluated the individual identities activated in the conflict and sought to evaluate his hierarchical position in his salience of identities. We thus propose the following:

Proposition 8a: When an individual understands that there is incongruence between some aspect of his or her identity and some aspect of the merged organization (individual-organization internal conflict), there is a state of individual-organization identity conflict, which tends to lead the individual to evaluate the salience of his or her individual identities.

In the case described above, the respondent said that, as important as his position was in the church, work was considered more salient in his hierarchy of identities. In this case, the conflict was resolved, and the individual felt free to remain in the organization, thus producing what we call individual-organization internal balance. However, when this balance does not occur, the state of individual-organization internal conflict remains. Thus, we propose as follows:

Proposition 8b: When evaluating the salience of individual identities during an individual-organization internal conflict, the most salient individual identity adjusts to the aspect of the organizational identity that generated the conflict, and individual-organization internal balance is established. Otherwise, the conflict remains.

\section{DISCUSSION}

The present study sought to understand the boundary dynamics between the organizational and individual identities that are negotiated in mergers. To achieve our objective, we developed a grounded theory, presented through propositions, which synthesized the following ideas: the degree of permeability between the internal and external boundaries between the organizations involved in a merger determines the types of episodic events and permanent states of conflict between the organizational identities. The merging organizations may adopt actions to negotiate the boundaries between the involved identities to minimize the degree of incongruence 
between the entities. Furthermore, the degree of (in)congruence between individual identities and the identity of the merged organization influences how individuals make use of more segmented or integrated boundaries between their personal identities and the organizational identity and their decision about whether they will remain in the merged organization. In some cases, different aspects of an individual's identity may conflict with some aspects of the organizational identity, which can lead the individual to a personal dilemma.

With regard to the literature on the boundary dynamics between identities in the context of work (Kreiner et al., 2006), this study also provided significant advances. Previous studies on the topic examined the boundary dynamics between personal and professional identities in different contexts (e.g., Araujo, Tureta, \& Araujo, 2015) and between organizational and individual identities (Kreiner et al., 2006). However, this study was the first to adopt boundary theory to analyze the interface between organizationorganization identities. The concept of organizational boundary work appears to be promising for the literature on identities in mergers as well as for the classification performed in the grounded theory presented in terms of identity stability/change and the degree of permeability of the boundaries between identities analyzed at different levels.

Moreover, we also analyzed the relationship between individual and organizational identity boundaries, which is particularly innovative for the literature on the human side of mergers. The fact that we also considered the individual-organization dynamics in a multi-level analysis allowed us to position individuals not as mere passive agents and recipients of identities constructed at the organizational level, but as subjects responding to identity pressures and initiating boundary dynamics (Clark, 2000). This analysis thus revealed decisions about identity and permanence conflicts in organizations that were experienced by individuals in a merger context.

With regard to the social constructionist perspective for the study of identities in mergers, this study made advances by proposing new understandings about how inter-organizational and individual-organizational boundary dynamics contribute to more or less homogenous constructions of "who we are" (Dutton et al., 1994; Gioia et al., 2000). As in previous study, we consider organizational identity from both central and distinct perspectives as well as from a multiple perspective derived from the interaction between individuals in different situations, hierarchical positions and organizational roles. However, we made advances by applying this idea to the merger context. This research belongs to the group of studies on 
organizational identity, which was classified by Pratt and Foreman (2003) as an "aggregate" perspective where collective identities are constructed in the minds of the organization's individual members; thus, it is the result of a compilation of individual views. In this study, we addressed aggregate groups at both a broad (organizational identity) and more restricted level (each of the multiple organizational identities). However, unlike what is usually proposed in studies from an "aggregate" perspective (He \& Brown, 2013), we did not find identities to be very stable. The boundary perspective allowed us to identify how collective identities can become more or less stable according to their degree of permeability.

In general, our study contributes to a holistic and comprehensive vision of how the boundaries between identities at the organizational and individual levels contribute to identity formation and the retention of individuals in the new merged organization.

\section{FINAL CONSIDERATIONS}

\subsection{Practical Implications}

This study has some implications for managing identities in mergers. The discussion about the relationships between organizational identities during a merger allow those responsible for evaluating a merger's feasibility to consider an analytic framework to anticipate the different types of conflicts that may arise, not only at the level of the organizations' distinctiveness but also at the level of socialization. Although it was not considered in any depth in this study, the concept of organizational boundary work also deserves to be explored in practical terms so that the idea of boundaries is considered when planning actions to manage organizational identities.

As for the process of managing the interface between individual identity and the merged organization's identity, this study makes it possible to analyze the conditions that tend to lead to identity balance and conflict. It is up to organizations to be aware of the internal and external boundary dynamics between individuals and the organization so that they can avoid unintended turnover in these cases. Moreover, the fact that some individuals will experience conflicts between their individual multiple identities should be regarded as natural. Organizations should be aware of those who continue working even when they are in a condition of conflict due to factors such as financial need or difficulty moving to other organizations. 


\subsection{Limitations and future research}

This study has limitations that open paths for future research possibilities. First, although we have presented organizational boundary work tactics as a relevant category for understanding how organizations undergoing a merger address different types of identity conflicts, we have not explored the ways in which the social actors involved in this process negotiate these boundaries. Future research could explore the strategies organizations use to create, maintain and transform the organization's internal and external boundaries to facilitate the process of constructing a state of organizational and individual identity balance. In this sense, exploring corporate communication theories (Balmer \& Dinnie, 1999) could be a suitable way to gain a better understanding of this aspect at the level of organizational core identity. Negotiations at the level of internal multiple identities could be explored according to role theory.

Second, we constructed this grounded theory using a sample of organizations based in a specific geographic and cultural context-Brazil. It is possible that other properties and categories could emerge if the study was conducted in other environments (Lodorfos \& Boateng, 2006). It is thus suggested that studies in other cultures should be conducted so that the results can be expanded to include some other culture-dependent categories that have not been identified in this study.

Third, while using the boundary perspective to simultaneously analyze organizational and individual identities that is consistent with the symbolic interactionist perspective, it may be incompatible when using other perspectives such as speech analysis, which explores questions regarding how power, discourse and subjectivity permeate the creation of discourses about how identity definitions are constructed (Kreiner et al., 2006). These questions were not explored in this study, and we believe that the organizational and individual identity (re)construction process in the merger context could be explored using discursive approaches in future studies. 


\section{IDENTIDADES INDIVIDUAIS E ORGANIZACIONAIS EM CONTEXTO DE FUSÕES: UMA PERSPECTIVA BASEADA NA TEORIA DE FRONTEIRAS}

\section{RESUMO}

Objetivo: Compreender a dinâmica de fronteiras entre identidades individuais e organizacionais que são negociadas em fusões.

Originalidade/relevância: Este foi o primeiro estudo a explorar as fronteiras entre identidades individuais e organizacionais em contexto de fusões.

Principais aspectos metodológicos: Os resultados são apresentados como uma teoria fundamentada, baseada em entrevistadas com 64 indivíduos de 16 organizações distintas que passaram por fusões.

Síntese dos principais resultados: Nós analisamos conflito, intrusão, distância e equilíbrio como consequências de (in)congruências entre fronteiras externas e internas de organizações e discutimos como elas podem minimizar conflitos de identidade individuais e organizacionais (da empresa resultante da fusão) por meio de gestão de fronteiras. Além disso, nós discutimos as relações entre as fronteiras de identidade organizacionais e individuais. A teoria fundamentada que desenvolvemos sustenta que o grau de permeabilidade entre as fronteiras internas e externas das organizações envolvidas em uma fusão determinam o tipo de eventos episódicos e os estados permanentes de conflito entre as identidades organizacionais. Em geral, nosso estudo contribui para uma visão holística e compreensiva a respeito de como as fronteiras entre identidades de nível individual e organizacional influenciam a formação da identidade e para a retenção de indivíduos na nova organização resultante da fusão. Sugestões para a prática e para pesquisas futuras são apresentadas.

\section{PALAVRAS-CHAVE}

Fronteiras. Fusão. Identidade organizacional. Identidade individual. Teoria fundamentada nos dados. 


\section{REFERENCES}

Albert, S., \& Whetten, D. A. (1985). Organizational identity. In B. Staw \& L. L. Cummings (Eds.), Research in organizational behavior (vol. 7, pp. 263295). Greenwich (CT): JAI Press.

Allen, V. L., Wilder, D. A., \& Atkinson, M. L. (1983). Multiple group membership and social identity. In T. R. Sarbin \& K. E. Scheibe (Eds.), Studies in social identity (pp. 92-115). New York (NY): Praeger.

Araujo, B. F. B., Tureta, C. A., \& Araujo, D. A. B. (2015). How do working mothers negotiate the work-home interface? Journal of Managerial Psychology, 30, 565-581. doi:10.1108/JMP-11-2013-0375

Ashforth, B. E., Kreiner, G. E., \& Fugate, M. (2000). All in a day's work: Boundaries and micro role transitions. Academy of Management Review, 25, 472-491. doi:10.5465/AMR.2000.3363315

Balmer, J. M., \& Dinnie, K. (1999). Corporate identity and corporate communications: The antidote to merger madness. Corporate Communications: An International Journal, 4, 182-192. doi:10.1108/13563289910299300

Brown, A. D. (2015). Identities and identity work in organizations. International Journal of Management Reviews, 17, 20-40. doi:10.1111/ijmr. 12035

Brown, A. D. (2017). Identity work and organizational identification. International Journal of Management Reviews, 19, 296-317. doi:10.1111/ijmr. 12152

Burke, K. (1984). Permanence and change: An anatomy of purpose. Berkeley (CA): University of California Press.

Cho, B., Lee, D., \& Kim, K. (2014). How does relative deprivation influence employee intention to leave a merged company? The role of organizational identification. Human Resource Management, 53, 421-443. doi:10.1002/ hrm. 21580

Clark, S. C. (2000). Work/family border theory: A new theory of work/ family balance. Human Relations, 53, 747-770. doi:10.1177/0018726700 536001

Cornelissen, J. P. (2002). The merit and mischief of metaphor: A reply to Gioia, Schultz and Corley. British Journal of Management, 13, 277-279. doi:10.1111/1467-8551.00244

Curchod, C., Patriotta, G., \& Neysen, N. (2014). Categorization and identification: The identity work of 'business sellers' on eBay. Human Relations, 67, 1293-1320. doi:10.1177/0018726713516376 
Dick, R., Ullrich, J., \& Tissington, P. A. (2006). Working under a black cloud: How to sustain organizational identification after a merger. British Journal of Management, 17, S69-S79. doi:10.1111/j.1467-8551.2006.00479.x

Dreiss, J. E. (1986) Building cohesiveness in an adolescent therapy group. Journal of Child and Adolescent Psychotherapy, 3, 22-28.

Dutton, J. E., Dukerich, J. M., \& Harquail, C. V. (1994). Organizational images and member identification. Administrative Science Quarterly, 39, 239263. doi: $10.2307 / 2393235$

Fiol, C. M. (2002). Capitalizing on paradox: The role of language in transforming organizational identities. Organization Science, 13, 653-666. doi:10.1287/orsc.13.6.653.502

Fiol, M. A. (1989). Semiotic analysis of corporate language: Organizational boundaries and joint venturing. Administrative Science Quarterly, 34, 277-303. doi:10.2307/2989899

Gioia, D. A., Schultz, M., \& Corley, K. G. (2000). Organizational identity, image, and adaptive instability. Academy of Management Review, 25, 63-81. doi:10.5465/AMR.2000.2791603

Gjerde, S., \& Ladegård, G. (2018). Leader role crafting and the functions of leader role identities. Journal of Leadership \& Organizational Studies, 32, 1-16.

Glaser, B., \& Strauss, A. (1967). The discovery of grounded theory: Strategies for qualitative inquiry. Chicago (IL): Aldine.

Glynn, M. A. (2000). When cymbals become symbols: Conflict over organizational identity within a symphony orchestra. Organization Science, 11, 285-298. doi:10.1287/orsc.11.3.285.12496

Hall, D. T., \& Richter, J. (1988). Balancing work life and home life: What can organizations do to help? The Academy of Management Executive, 2, 213-223. doi:10.5465/AME.1988.4277258

Hartmann, E. (1991). Boundaries in the mind: A new psychology of personality. New York (NY): Basic Books.

Harvey, W. S., Morris, T., \& Müller Santos, M. (2017). Reputation and identity conflict in management consulting. Human Relations, 70(1), 92-118. doi:10.1111/ijmr.12148

He, H., \& Brown, A. D. (2013). Organizational identity and organizational identification: A review of the literature and suggestions for future research. Group \& Organization Management, 38, 3-35. doi:10.1177/1059601112473 815 
Horton, K. E., Bayerl, P. S., \& Jacobs, G. (2014). Identity conflicts at work: An integrative framework. Journal of Organizational Behavior, 35, S6-22. doi:10.1002/job.1893

Hsu, G., \& Elsbach, K. D. (2013). Explaining variation in organizational identity categorization. Organization Science, 24, 996-1013. doi:10.1287/ orsc. 1120.0779

Joseph, J. (2014). Managing change after the merger: The value of pre-merger ingroup identities. Journal of Organizational Change Management, 27, 430-448. doi:10.1108/JOCM-10-2013-0184

Kjærgaard, A., Morsing, M., \& Ravasi, D. (2011). Mediating identity: A study of media influence on organizational identity construction in a celebrity firm. Journal of Management Studies, 48, 514-543. doi:10.1111/j. 1467-6486.2010.00954.x

Kreiner, G. E., Hollensbe, E. C., \& Sheep, M. L. (2006). On the edge of identity: Boundary dynamics at the interface of individual and organizational identities. Human Relations, 59, 1315-1341. doi:10.1177/0018726706071525

Lodorfos, G., \& Boateng, A. (2006). The role of culture in the merger and acquisition process: Evidence from the European chemical industry. Management Decision, 44, 1405-1421. doi:10.1108/00251740610715722

MacLean, T. L., \& Webber, S. S. (2015). Navigating multiple identities across multiple boundaries: A cross-level model of organizational identification. Journal of Management Inquiry, 24, 156-173. doi:10.1177/1056492614546222

Markus, H., \& Kunda, Z. (1986). Stability and malleability of the self-concept. Journal of Personality and Social Psychology, 51, 858-866. doi:10.1037/ 0022-3514.51.4.858

Petriglieri, J. L. (2011). Under threat: Responses to and the consequences of threats to individuals' identities. Academy of Management Review, 36, 641662. doi:10.5465/amr.2009.0087

Pratt, M. G., \& Foreman, P. O. (2000). Classifying managerial responses to multiple organizational identities. Academy of Management Review, 25, 18-42. doi:10.5465/AMR.2000.2791601

Rau, B. L., \& Hyland, M. A. M. (2002). Role conflict and flexible work arrangements: The effects on applicant attraction. Personnel Psychology, 55, 111-136. doi:10.1111/j.1744-6570.2002.tb00105.x

Ravasi, D., \& Schultz, M. (2006). Responding to organizational identity threats: Exploring the role of organizational culture. Academy of Management Journal, 49, 433-458. doi:10.5465/AMJ.2006.21794663 
Rouzies, A. (2011). Antecedents of employees' identification with a merger: A three-stage empirical study. International Studies of Management $\mathcal{E}$ Organization, 41, 25-41. doi:10.2753/IMO0020-8825410302

Schneider, S. C. (1991). Managing boundaries in organizations. In M. F. R. Kets de Vries (Ed.), Organizations on the couch: Clinical perspectives on organizational behavior and change (pp. 169-190). San Francisco (CA): Jossey-Bass.

Sillince, J. A., \& Brown, A. D. (2009). Multiple organizational identities and legitimacy: The rhetoric of police websites. Human Relations, 62, 1829-1856. doi:10.1177/0018726709336626

Stryker, S. (1981). Symbolic interactionism: Themes and variations. In M. Rosenberg \& R. H. Turner (Eds.), Social psychology: Sociological perspectives (pp. 3-29). New York (NY): Basic Books.

Tajfel, H., \& Turner, J. C. (1986). The social identity theory of intergroup behavior. In S. Worchel \& W. G. Austin (Eds.), Psychology of intergroup relations ( ${ }^{\text {nd }}$ ed., pp. 7-24). Chicago (IL): Nelson Hall.

Terry, D. J., Carey, C. J., \& Callan, V. J. (2001). Employee adjustment to an organizational merger: An intergroup perspective. Personality and Social Psychology Bulletin, 27, 267-280. doi:10.1177/0146167201273001

Ullrich, J., Wieseke, J., \& Dick, R. V. (2005). Continuity and change in mergers and acquisitions: A social identity case study of a German industrial merger. Journal of Management Studies, 42, 1549-1569. doi:10.1111/j.14676486.2005.00556.x

Vieru, D., \& Rivard, S. (2014). Organizational identity challenges in a post-merger context: A case study of an information system implementation project. International Journal of Information Management, 34, 381-386. http:// dx.doi.org/10.1016/j.ijinfomgt.2014.02.001

\section{) AUTHORS NOTE}

Bruno Felix, Business Administration from the Social and Applied Sciences Center (CCSA), Universidade Presbiteriana Mackenzie (UPM); Mário S. Bento, Business Administration College, Fucape Business School.

Bruno Felix is now Associate Professor at Fucape Business School.

Correspondence concerning this paper should be addressed to Bruno Felix, Avenida Fernando Ferrari, 1358, Boa Vista, Vitória, Espírito Santo, Brazil, CEP 29075-505.

E-mail: bfelix@fucape.br 
Bruno Felix, Mário S. Bento

\section{EDITORIAL BOARD}

Editor-in-chief

Silvio Popadiuk

Associated Editor

Fabiano Larentis

Technical Support

Vitória Batista Santos Silva

\section{EDITORIAL PRODUCTION}

Publishing Coordination Irina Migliari

Language Editor

Daniel Leão

Editorial Trainee

Maria Luiza Vanz

Layout Designer

Emap

Copyeditor

Irina Migliari
Graphic Designer Libro 